IP Periodica Polytechnica

Mechanical Engineering

62(4), pp. 312-319, 2018

https://doi.org/10.3311/PPme.12372

Creative Commons Attribution (i)

RESEARCH ARTICLE

\section{Optimization of the Operating and Design Conditions to Reduce the Power Consumption in a Vessel Stirred by a Paddle Impeller}

\author{
Houari Ameur $^{1 *}$, Youcef Kamla², Djamel Sahel ${ }^{3}$
}

Received 08 April 2018; accepted 26 July 2018

\begin{abstract}
Design of the impeller blade is a determining factor in power consumption and mixing quality, which determines consequently the cost of the mixing operation. This study explores the flow patterns and the power required for stirring a Newtonian fluid by paddle impellers. Investigations are carried out via three dimensional (3D) numerical simulations. Effects of the blade curvature, blade diameter, blade number and Reynolds number are analyzed. The curved blade is found to be more efficient to reduce the power consumption, compared with the straight blade. A new correlation is proposed for predicting the power required with two-curved-bladed impellers. The straight and very large blade creates a dead zone in the space between the blade tip and the vertical wall of vessel. This issue may be overcome by the curved blade, which increases consequently the well-mixed region size. A wider well-mixed region may be obtained with the larger curved blade, but with an additional energy cost.
\end{abstract}

\section{Keywords}

impeller design, flow patterns, power consumption, curvedblade, paddle impeller

\footnotetext{
${ }^{1}$ Institute of Science and Technology, University Center Salhi Ahmed, Ctr Univ Naâma, PB 66, 45000, Algeria

${ }^{2}$ Department of Science and Technology, Faculty of Technology, Unisversity Hassiba Ben Bouali of Chlef, Algeria

${ }^{3}$ Department of Technical Sciences, University Amar Thilidji of Laghouat, Algeria

*Corresponding author, e-mail address: houari_ameur@yahoo.fr
}

\section{Introduction}

The mechanically agitated vessel is widely used in many industrial operations such as in the chemical, biochemical, pharmaceutical, food, paint, wastewater treatment, petroleum and other industries. Due to the complexity of the three-dimensional hydrodynamics inside the agitated vessels, many problems are still addressed. One of the main problems often encountered is how to reduce the power required for achieving the mixing operation.

The power number is a global macro-mixing parameter depending largely on the flow structures, which are highly influenced by the impeller design [1]. Many researchers interested to the study of power consumption in several impellers and applications. Among others, Yang et al. [2] for a novel grid disc impeller, Ghotli et al. [3] for six-curved bladed turbines, Bao et al. [4] for a coaxial mixer, Machado and Kresta [5] for confined impellers (A310 and Intermig); for Rushton turbines [6-9], pitched blade turbines [10-13], retreat curve impellers [14], Intermig impeller [15].

Design of the impeller blade is an important parameter to be investigated in mixing systems [16-24]. Due to the different blade shapes available in industries, the fluid flows inside the vessel and the power consumed change, increasing the necessity of optimizing the blade geometry.

Almost all studies published were stick only to a standard two-bladed impeller having a straight blade. Youcefi [18] performed experiments with Newtonian and viscoelastic fluids. Abid et al. [19] and Bouzit et al. [20] simulated the 3D flow fields inside a vessel filled with a Newtonian fluid and stirred by a two-straight-bladed impeller. Ameur and Bouzit [21] proposed a new correlation for predicting the power required when stirring shear thinning fluids by two-straight-bladed impellers. With the same impeller, Youcefi and Youcefi [22] measured the power consumption and mixing times in viscoelastic fluids when changing the blade height.

From laminar to turbulent flow regimes, Kato et al. [25] studied the effect of Newtonian liquid height on the power consumption of straight paddle impellers. Haitsuka et al. [26] measured the mass transfer volumetric coefficient and power 
consumption in vessels equipped with different large-paddle stirrers under aeration. They reported that the wide paddle stirrer did not decrease the aerated power consumption, because no wide cavity was created.

In eccentric mixing, Tanabe et al. [27] explored the torque and horizontal load on a straight paddle impeller. Their results of time series revealed the periodic oscillation of the torque and horizontal load. By using the CFD method, the effects of the blade width, the number of blades and the rotational speed on the starting torque of a vertical paddle impeller were explored by Nishi et al. [28]. For Newtonian liquids mixed in vessels with a dished bottom, Furukawa et al. [29] correlated the power consumption and mixing patterns for straight large paddle impellers. For complex fluids and straight paddle impellers, Ameur [30,31] studied the effects of several geometrical and operating conditions including the blade height, the blade width and the blade attack angles on the flow patterns and power consumption.

Liu et al. [23] studied the performance of a novel large twobladed impeller, which is based on the Maxblend and Fullzone impellers. The new design has adaptability to viscous systems, as reported by these authors.

The optimum design of a mixing system for minimum costs is achieved by the correct choice of the impeller geometry and its location, of the vessel shape, impeller rotational speed and fluid properties [32-36]. Our search in the literature shows that no paper is published dealing with a two-curved-bladed impeller. So, it is necessary to introduce enhancements in the blade design in order to increase the energy efficiency of the mixer.

Thus, the purpose of the present study is to model a stirred tank driven by a large two-bladed impeller. The effect of blade curvature on the power consumption and the flow fields is investigated.

\section{Details on the mixing system}

Geometry of the stirred system consists of a cylindrical tank with a flat bottom having a diameter $(D)$ equal to $300 \mathrm{~mm}$ and a height $H / D=1.66$. The liquid level is kept equal to the vessel height. The stirrer has two blades with a height $T / D=1.6$ and it is placed at a distance $c / D=0.066$ to not scrape the bottom of the tank. The blade thickness $\left(\mathrm{b}_{\mathrm{t}}\right)$ is taken as $b_{\mathrm{t}} / D=0.0066$. Water liquid is used as a working fluid (density $\rho=997\left[\mathrm{~kg} / \mathrm{m}^{3}\right]$ and dynamic viscosity $\mu=8.899 \times 10^{-4}[\mathrm{~kg} / \mathrm{ms}]$ ).

Several design parameters have been changed, it concerns: the blade curvature, its diameter and its number. Six geometries were realized for testing the blade curvature $\left(b_{c}\right)$ effect, which are: $b_{\mathrm{c}}{ }^{*}=b_{\mathrm{c}} / D=0,0.016,0.033,0.05,0.066$ and 0.116 , respectively. Other four geometries were performed when varying the blade diameter $(d)$, which are: $d / D=0.5,0.66,0.82$ and 0.98 . And finally, the blade number $(\alpha)$ is changed from 2 to 8 (six geometries, $\alpha=2,3,4,5,6$ and 8 ).

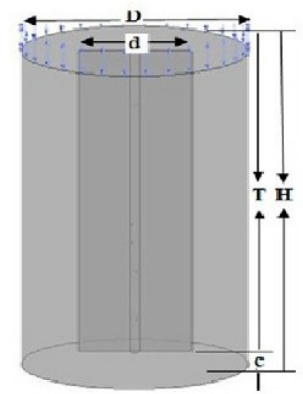

Two-Straight-Bladed impeller (TSB)

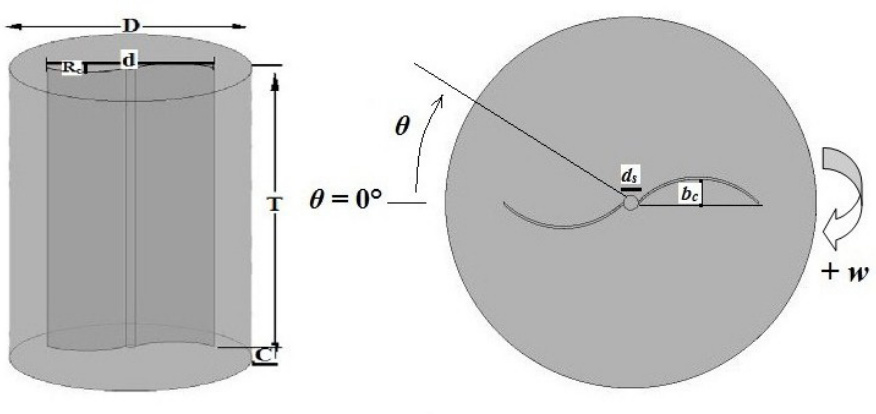

Two-Curved-Bladed impeller (TCB)

Fig. 1 Geometry of the mixing system

\section{Mathematical equations}

For a Newtonian fluid, the Reynolds number $(R e)$ is defined as:

$$
R e=\frac{\rho N d^{2}}{\eta}
$$

where $\rho$ is the density and $N$ is the rotational speed of the impeller. In this study, the Reynolds number is changed from 0.1 to 30 (i.e. the flow regime remains laminar).

The power consumption $(P)$ is calculated by integration on the viscous dissipation $\left(Q_{v}\right)$ in all the vessel volume as:

$$
P=\eta \int_{\text {vessel volume }} Q_{v} d v
$$

The power number $(N p)$ is calculated as:

$$
N_{P}=\frac{P}{\rho N^{3} d^{5}}
$$

\section{Computational model}

Computations were achieved with the help of the CFD code CFX 16.0 (Ansys Inc.). This computer program is based on the finite volume method to solve the equations of momentum conservation. The geometry of the mixing system is created by the pre-processor ICEM CFD 16.0 and the computational domain is then divided into small grids (tetrahedral meshes, Fig. 2).

The mesh density has an extremely important effect on the accuracy of the predicted results. Therefore, various mesh tests were performed before beginning any investigation. The first mesh had about 489,521 elements. This density was increased 
by about two times (992,256 elements) and two times again (1,482,512 elements). The velocity at the blade tip and the power consumption were determined for each mesh density. The obtained results revealed that the second mesh $(992,256$ elements) is sufficient, since the variations did not exceed $2 \%$ (Table 1). For all geometrical configurations studied, the mesh density was varied from 990,000 to $1,010,000$ elements.

The numerical approaches adopted play an important role in accurate prediction of the mixing characteristics. In our simulations, the mixing system is modeled by the Rotating Reference Frame (RRF) technique, i.e. the stirrer is modeled as stationary and the vessel walls are modeled as rotating zones. This technique is suitable for unbaffled stirred tanks. Several studies have been achieved with the RRF approach for unbaffled vessels and accurate results were obtained [37-41]. The impeller rotation speed is low and the flow regime is laminar. The vessel is considered as covered and the liquid height is kept equal to the vessel height. So the interaction with air is avoided and single phase simulations are performed. For the convection terms, the second order upwind scheme was selected. A pressure-correction method of the type Semi-Implicit Method for Pressure Linked Equations Consistent (SIMPLEC) is used to perform the pressure-velocity coupling. Other details of the numerical method performed in our investigations can be found in our previous paper [42].

Calculations were performed in a platform with Core i7 CPU 2.20 GHz and 8.0 GB of RAM. Simulations were considered to be converged when the residual targets of velocities and pressure drop below $10^{-7}$. Most simulations converged after 1000-1500 iterations and 5-6 hours in CPU time.

Table 1 Details on mesh tests

\begin{tabular}{llll}
\hline & Mesh 1 & Mesh 2 & Mesh 3 \\
\hline Number of grid elements & 489,521 & 992,256 & $1,482,512$ \\
$V_{\max }^{*}$ & 0.64923 & 0.66013 & 0.66124 \\
$N p$ & 11.59 & 12.32 & 12.41 \\
Computational time [second] & 10,526 & 18,523 & 32,957 \\
\hline
\end{tabular}

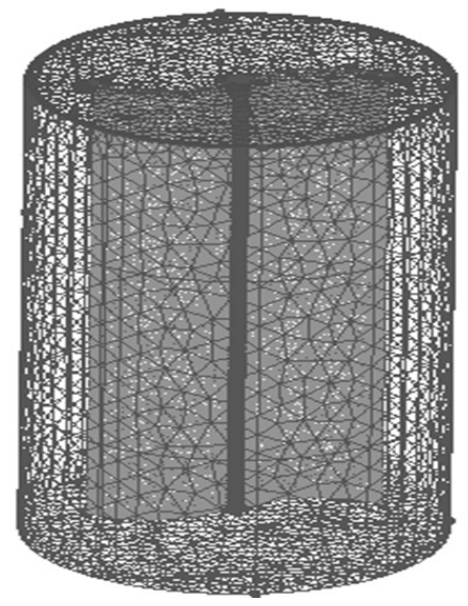

Fig. 2 Meshes generated (tetrahedral grids)

\section{Validation of the numerical results}

Before starting the numerical investigation, it is necessary to check the reliability of the computer program used. To this end, reference was made to the experimental work of Youcefi [18]. With the same geometry of the mixing system and the same fluid used by Youcefi, the variations of power consumption vs. Reynolds number and the tangential velocity vs. vessel radius are presented in Figs. 3a and 3b, respectively. As remarked on these figures, the comparison between our predicted results and the other experimental data shows a satisfactory agreement.

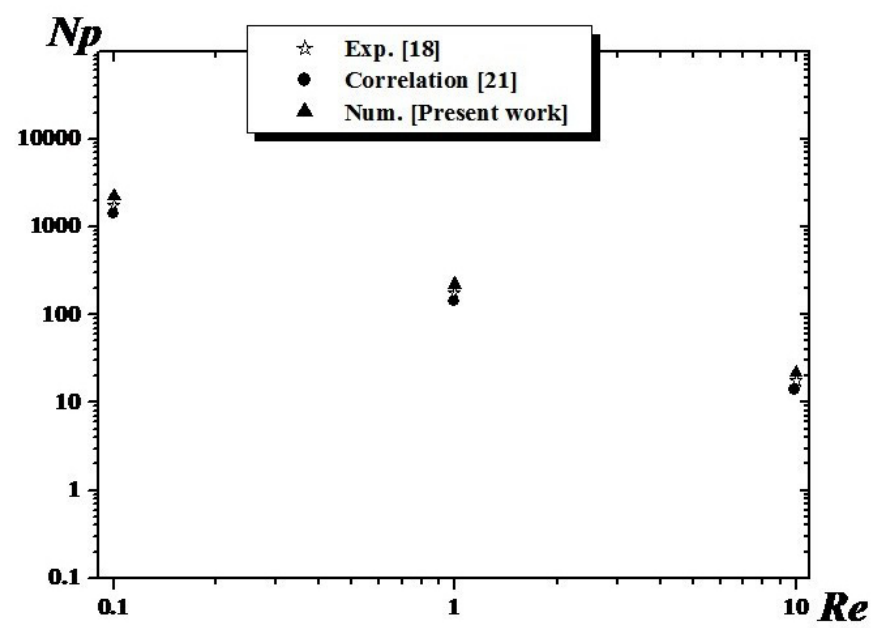

(a)

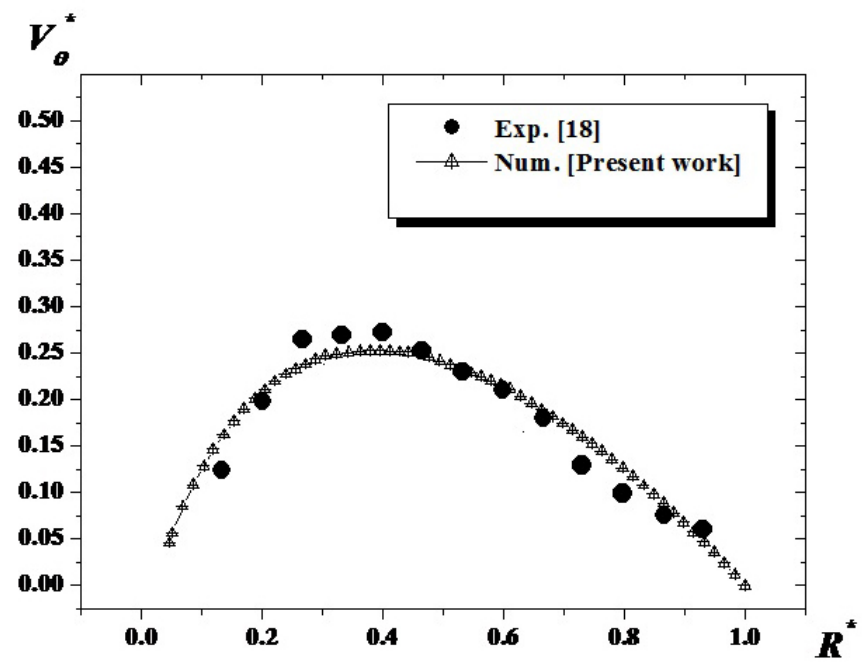

(b)

Fig. 3 Validation of the predicted results, (a) Power number vs. Reynolds number, (b) Tangential velocity vs. the vessel radius, at $R e=04$

\section{Results and discussion}

\subsection{Effect of the blade curvature}

The main purpose of the present paper is to investigate the effects of some design parameters on the power consumption and mixture quality in a stirred tank reactor.

We are interested to the mechanical stirring of viscous fluid with a paddle agitator. The size of the impeller blade requires a high power to complete the mixing operation. So, as a solution 
to this issue, we suggest a new design: it is the curved blade instead of the classic straight blade.

In this section, we explore the effectiveness of this design by realizing six geometries and which are $b_{c}{ }^{*}=b_{c} / D=0,0.016$, $0.033,0.05,0.066$ and 0.116 , respectively. We note that the blade diameter is kept constant for these geometries.

On a horizontal plane located at the middle height of the tank (at the vertical coordinate $Z^{*}=Z / D=0.5$ ), the flow fields are shown in Fig. 4a. The velocity reaches its maximum at the blade tip for each case. For the case $b_{c}{ }^{*}=0$ (i.e. a straight blade), a dead zone appears on the extension line of the blade (near the vessel wall). If Reynolds number is low, the flow will rotate in block for this type of mixers, so that will create a dead zone near the vertical wall of the vessel.

The curved blade can overcome this issue as shown in Fig. 4a. With the same blade diameter, the size of the dead zone decreases with the curved blade $b_{c}{ }^{*}=0.066$, and more with a greater curvature $b_{c}{ }^{*}=0.116$. Consequently, an increase in the well-stirred region size will be obtained (Fig. 4b).
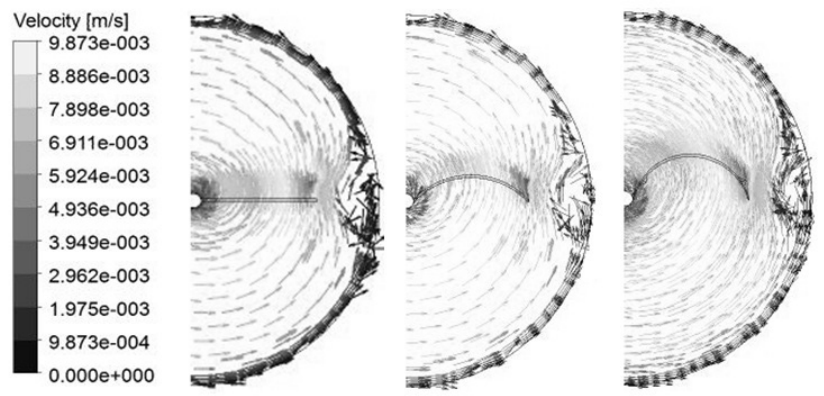

(A)
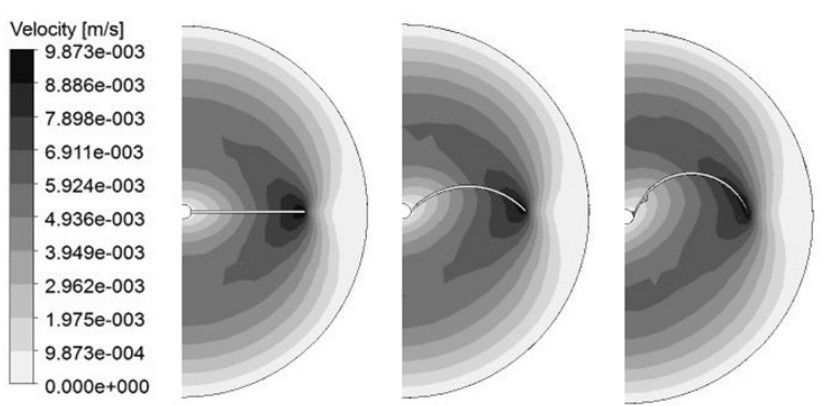

(B)
(a) $b_{c}^{*}=0$
(b) $b_{c}^{*}=0.066$
(c) $b_{c}^{*}=0.116$

Fig. 4 Velocity contours for $d / D=0.5, \operatorname{Re}=30, \alpha=2, Z^{*}=0.5$

The power drawn by a rotating stirrer has a significant role in designing the mixing systems. Preferred stirrers are those with the lowest power requirements [42]. Therefore, a comparison between stirrers with different geometries would be helpful for the best choice of the appropriate one.

The curved blade can be considered as a very valiant design, since the increase of the blade curvature reduces the viscous dissipation and consequently the power consumption (Fig. 5).
For example, for $R e=30$, the power numbers for the straight blade $\left(b_{\mathrm{c}}{ }^{*}=0\right)$ and the curved blade $\left(b_{\mathrm{c}}{ }^{*}=0.0116\right)$ are 7.47 and 2.35 , respectively, i.e. a reduction by more than three times.

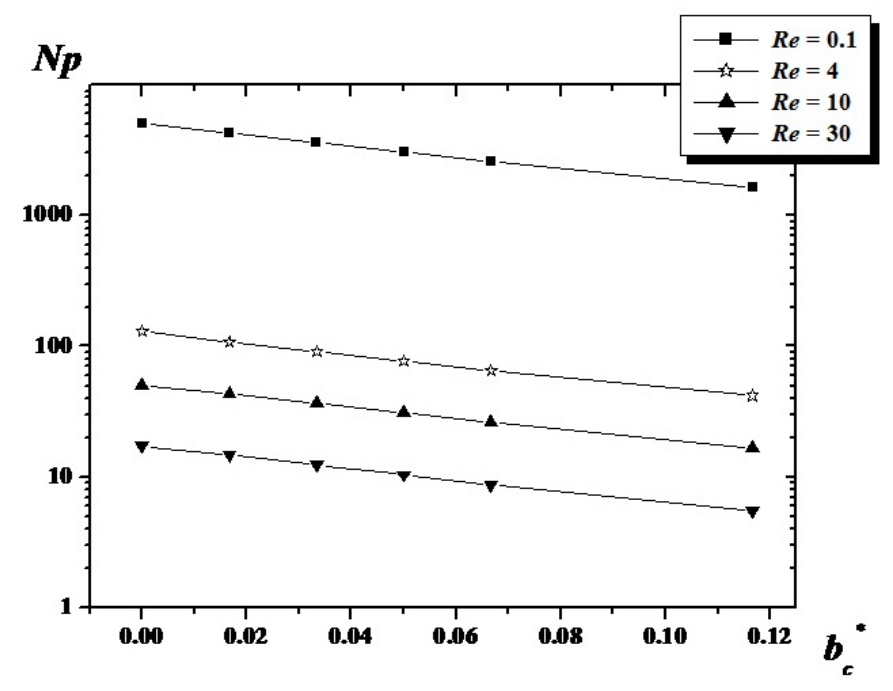

Fig. 5 Power number vs. blade curvature for different $R e$, at $d / D=0.66$

\subsection{Effect of diameter and length of the blade}

This type of mixer creates a tangential flow, i.e. the tangential velocity component dominates in the entire volume of the tank [20-22]. Based on this, changes in the tangential velocity are followed along the vessel radius for two angular positions $(\theta): \theta=0^{\circ}$ (on the extension of the blade, Fig. 6a) and $\theta=90^{\circ}$ (on the perpendicular mediator of the blade, Fig. $6 b)$. The maximum value of velocity is reached at the blade tip for all geometries (Fig. 6a). When moving away from the area swept by the impeller, the flow rate decreases continually until becoming neglected at the vessel wall.

At low Reynolds number and for a curved blade with a small diameter and length, a dead zone appears on the extension of the blade (Fig. 7). Increasing the diameter and length of the blade will decrease the size of the dead zone, giving then a large area of good mixtures, but with additional power consumption (Fig. 8).

For example, for $R e=10$, the power number for the curved blade $\left(b_{c}{ }^{*}=0.116\right)$ with diameter $d / D=0.5$ and 0.92 are 20.31 and 322.21 , respectively, i.e. an increase by more than 15 times.

\subsection{Effect of the blade number}

The number of blades is another parameter that can strongly influence the viscous dissipation and power requirements. Fig. 9 shows the variation in the power consumed for six impeller geometries with different numbers of blades $(\alpha)$, which are: $\alpha=2,3,4,5,6$ and 8. As clearly shown, the increase in blades number increases the power consumption. For example, the impeller with 8 straight blades of diameter $d / D=0.92$ requires more power, about 2.5 times more than a two-bladed impeller with the same diameter. 


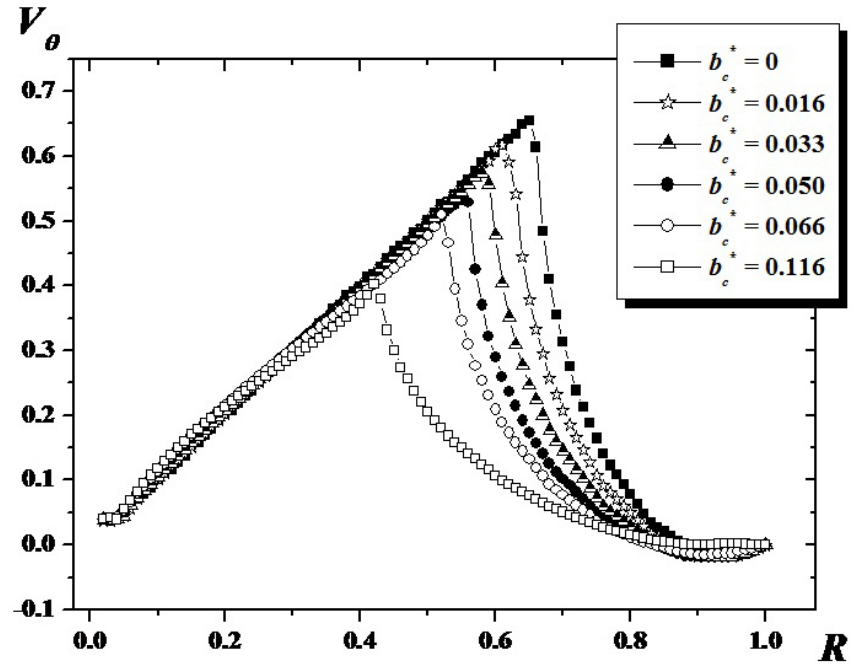

(a)

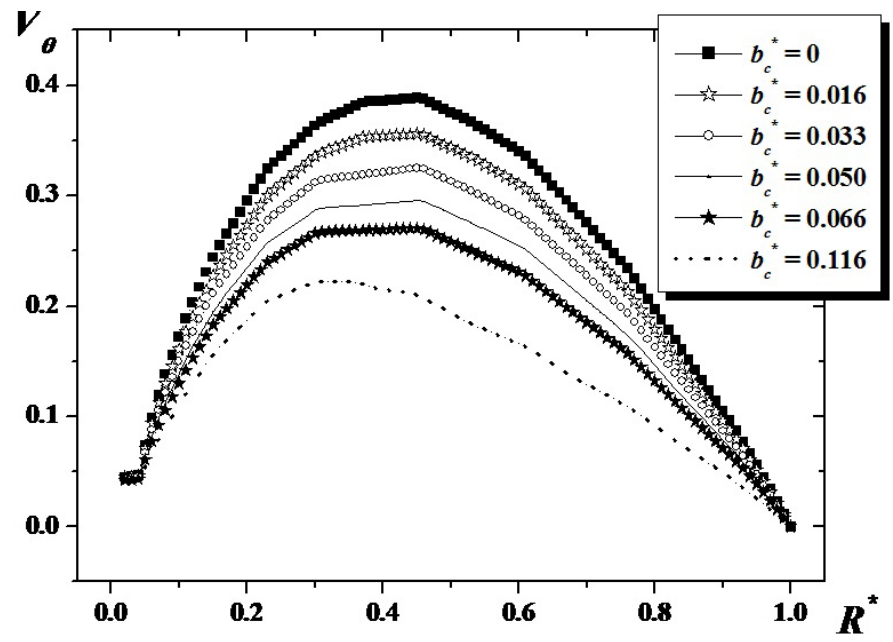

(b)

Fig. 6 Tangential velocity for $R e=30, \alpha=2, d / D=0.66, Z^{*}=0.85$, (a) $\theta=0^{\circ}$, (b) $\theta=90^{\circ}$

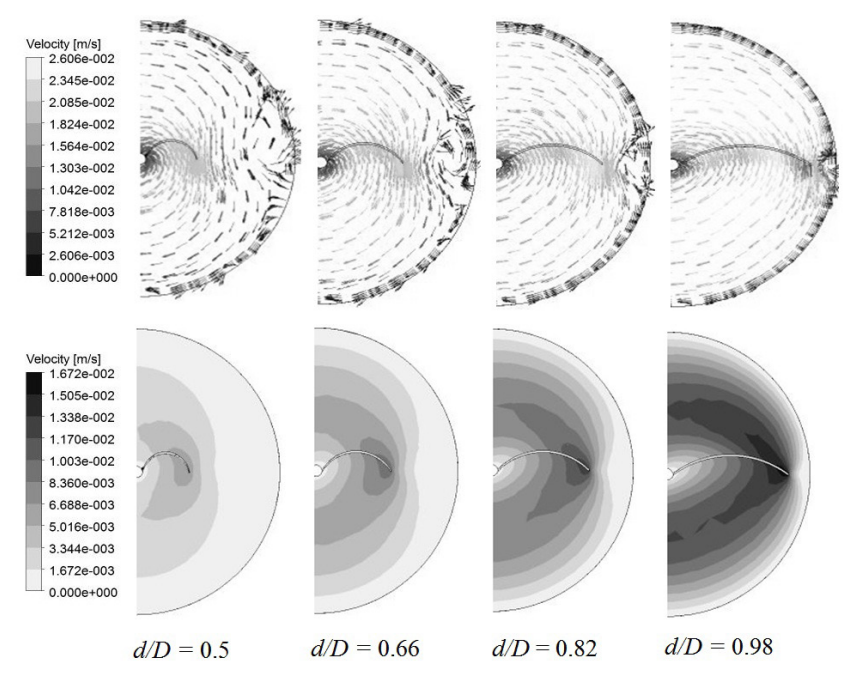

Fig. 7 Flow fields for $b_{\mathrm{c}}{ }^{*}=0.066, R e=10, \alpha=2$

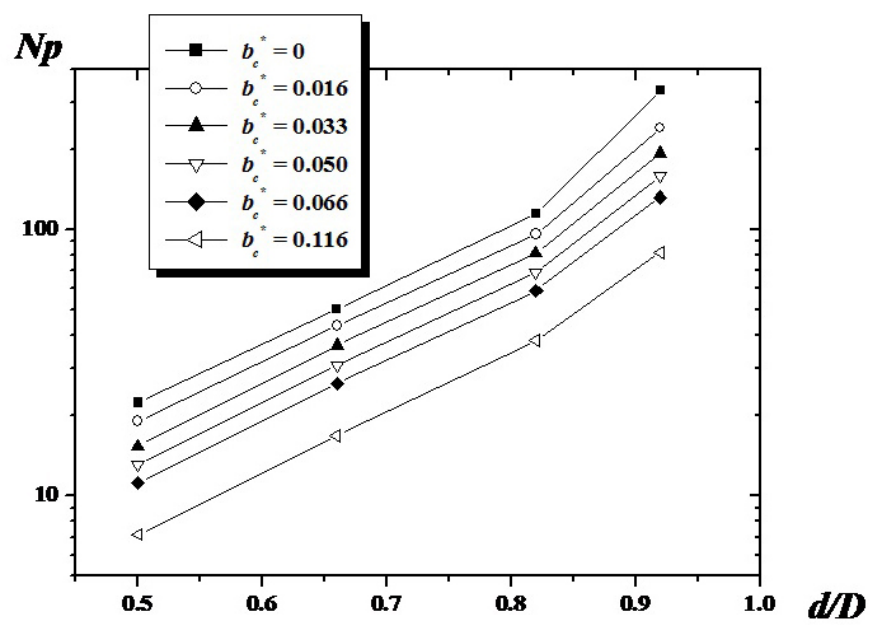

Fig. 8 Power number vs. blade diameter for different $b_{\mathrm{c}}{ }^{*}, \operatorname{Re}=10, \alpha=2$

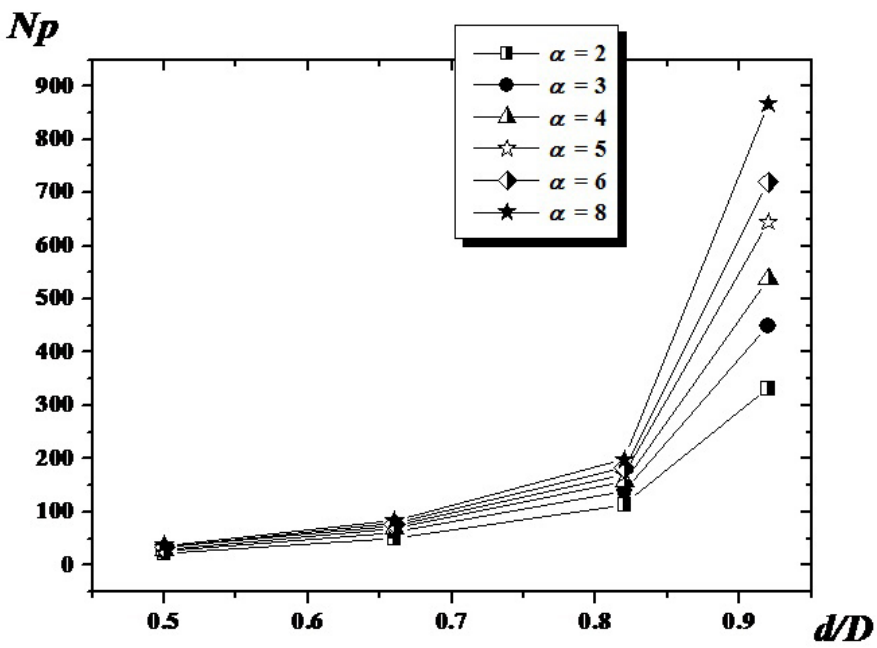

Fig. 9 Power number $(N p)$ vs. blade diameter $(d / D)$ for different blade numbers $(\alpha)$, at $R e=10, b_{\mathrm{c}}^{*}=0$

For $R e=10$ and an impeller with straight-blades of diameter $d / D=0.92$, the power numbers for the blade numbers $\alpha=2,3$, 4, 5, 6 and 8 are $N p=332.34,450.41,538.41,644.89,719.98$, and 866.35 , i.e. an increase by about $35 \%, 62 \%, 93 \%, 116 \%$, $160 \%$, respectively.

\subsection{Optimizing the mixing system}

The curved blade exhibits a very effective solution to minimize the power consumption if one wants to reduce the mixing time by using a mixer with a great number of blades.

As shown in Fig. 10, the power consumption may be kept constant if the curvature blade is increased at the same time with increasing the number of blades.

\subsection{Correlation}

$$
N p=16.74 R e^{-0.995} e^{\left(\frac{1}{D}\left(5.26 d-10.83 b_{c}\right)\right)}
$$


At the end of the manuscript, we propose a new correlation to predict the power required for the agitation of a viscous Newtonian fluid, while changing the Reynolds number, the blade curvature and its diameter. We compared the results obtained by the proposed correlation and those obtained by numerical simulations, and a good agreement was found (Fig. 11).

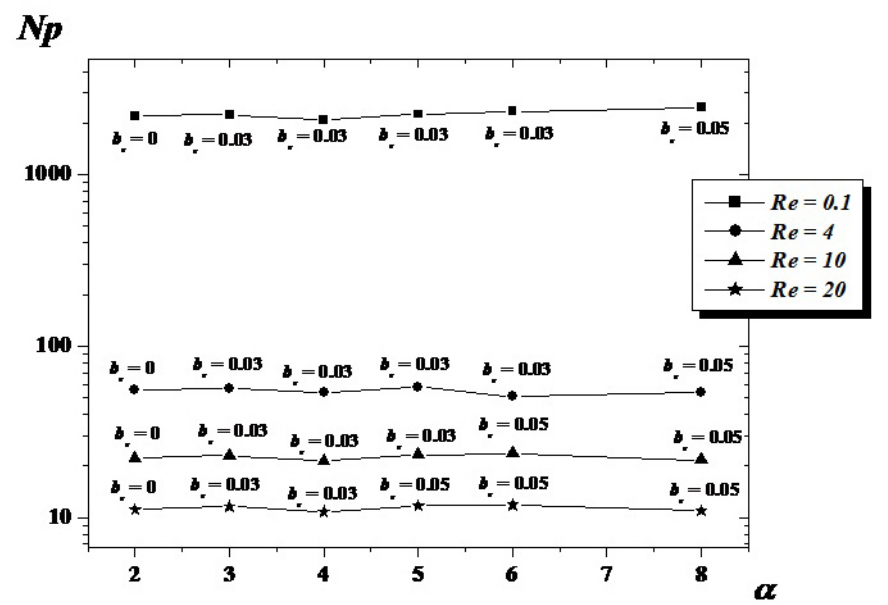

Fig. 10 Power number $(N p)$ vs. blade number $(\alpha)$ for different Re and $b_{c}^{*}$, $d / D=0.5$

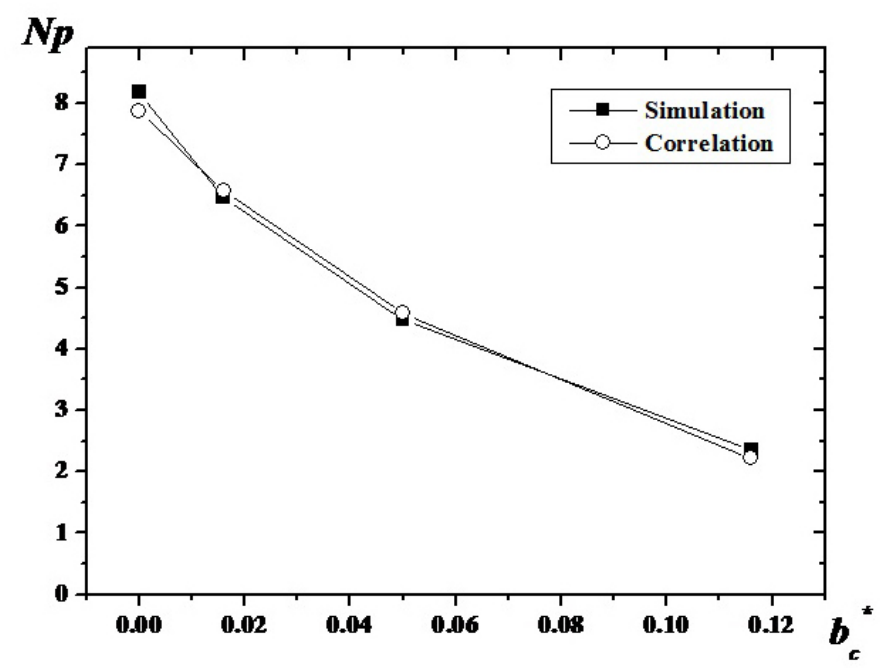

Fig. 11 Power number for $d / D=0.82, \operatorname{Re}=30$

\section{Conclusion}

Numerical simulations of viscous Newtonian fluid flows in a mechanically stirred tank were performed. Stirring is provided by a paddled impeller rotating at low speeds. The predicted results show that the impeller with two straight and wide blades generates a tangential flow. And if the impeller rotational speed is low, the flow rotates in block which yields a dead zone on the extension of the blade (near the vertical wall of the tank). The curved blade may reduce the size of these dead regions.

For the same blade diameter and the same Reynolds number, the increase of the blade curvature reduces greatly the power consumption.
For a curved blade with a small diameter and at low Reynolds number, the size of the good mixing zone is very small. The increase of the blade diameter of can extend this area (for the same $R e$ ), but with an additional energy cost.

The increased number of blades can reduce the mixing time, but it requires more energy. For example, the power consumption of an eight-straight-blade impeller is greater by about 2.5 times that the two-straight-bladed-impeller, for the same diameter, curvature and $R e$. As an optimized design, the power consumption may be kept almost constant, if we increase the blade curvature at the same time when increasing the number of blades.

\section{References}

[1] Qiao, S., Wang, R., Yang, X., Yan, Y. "CFD prediction of mean flow field and impeller capacity for pitched blade turbine." Transactions of the Tianjin University. 21(3), pp. 250-258. 2015. https://doi.org/10.1007/s12209-015-2408-X

[2] Yang, F. L., Zhou, S. J., Zhang, C. X. "Turbulent flow and mixing performance of a novel six-blade grid disc impeller." Korean Journal of Chemical Engineering. 32(5), pp. 816-825. 2015. https://doi.org/10.1007/s11814-014-0255-4

[3] Ghotli, R. A., Abdul Aziz, A. R., Ibrahim, S., Baroutian, S., Arami-Niya, A. "Study of various curved-blade impeller geometries on power consumption in stirred vessel using response surface methodology." Journal of the Taiwan Institute of Chemical Engineers. 44(2), pp. 192-201. 2013. https://doi.org/10.1016/j.jtice.2012.10.010

[4] Bao, Y., Lu, Y., Liang, Q., Li, L., Gao, Z., Huang, X., Qin, S. "Power demand and mixing performance of coaxial mixers in a stirred tank with CMC solution." Chinese Journal of Chemical Engineering. 23(4), pp. 623-632. 2015.

https://doi.org/10.1016/j.cjche.2015.01.002

[5] Machado, M. B., Kresta, S. M. "The confined impeller stirred tank (CIST): A bench scale testing device for specification of local mixing conditions required in large scale vessels." Chemical Engineering Research and Design. 91(11), pp. 2209-2224. 2013.

https://doi.org/10.1016/j.cherd.2013.06.025

[6] Basavarajappa, M., Draper, T., Toth, P., Ring, T. A., Miskovic, S. "Numerical and experimental investigation of single phase flow characteristics in stirred tanks using Rushton turbine and flotation impeller." Minerals Engineering. 83, pp. 156-167. 2015.

https://doi.org/10.1016/j.mineng.2015.08.018

[7] Ochieng, A., Onyango, M. S. "Homogenization energy in a stirred tank." Chemical Engineering and Processing: Process Intensification. 47(9-10), pp. 1853-1860. 2008.

https://doi.org/10.1016/j.cep.2007.10.014

[8] Kamla, Y., Bouzit, M., Ameur, H., Arab, M. I., Hadjeb, A. "Effect of the Inclination of Baffles on the Power Consumption and Fluid Flows in a Vessel Stirred by a Rushton Turbine." Chinese Journal of Mechanical Engineering. 30(4), pp. 1008-1016, 2017.

https://doi.org/10.1007/s10033-017-0158-5

[9] Ameur, H. "Modifications in the Rushton turbine for mixing viscoplastic fluids." Journal of Food Engineering. 233, pp. 117-125, 2018. https://doi.org/10.1016/j.jfoodeng.2018.04.005

[10] Ammar, M., Chtourou, W., Driss, Z., Abid, M. S. "Numerical investigation of turbulent flow generated in baffled stirred vessels equipped with three different turbines in one and two stage system." Energy. 36(8), pp. 5081-5093. 2011.

https://doi.org/10.1016/j.energy.2011.06.002 
[11] El-Hamouz, A., Cooke, M., Kowalski, A., Sharratt, P. "Dispersion of silicone oil in water surfactant solution: Effect of impeller speed, oil viscosity and addition point on drop size distribution." Chemical Engineering and Processing: Process Intensification. 48(2), pp. 633-642. 2009. https://doi.org/10.1016/j.cep.2008.07.008

[12] Ge, C.-Y., Wang, J.-J., Gu, X.-P., Feng, L.-F. "CFD simulation and PIV measurement of the flow field generated by modified pitched blade turbine impellers." Chemical Engineering Research and Design. 92(6), pp. 1027-1036. 2014. https://doi.org/10.1016/j.cherd.2013.08.024

[13] Montante, G., Moštěk, M., Jahoda, M., Magelli, F. "CFD simulations and experimental validation of homogenisation curves and mixing time in stirred Newtonian and pseudoplastic liquids." Chemical Engineering Science. 60(8-9), pp. 2427-2437. 2005. https://doi.org/10.1016/j.ces.2004.11.020

[14] Ameur, H. "Mixing of Shear Thinning Fluids in Cylindrical Tanks: Effect of the Impeller Blade Design and Operating Conditions." International Journal of Chemical Reactor Engineering. 14(5), pp. 1025-1034. 2016. https://doi.org/10.1515/ijcre-2015-0200

[15] Aubin, J., Xuereb, C. "Design of multiple impeller stirred tanks for the mixing of highly viscous fluids using CFD." Chemical Engineering Science. 61(9), pp. 2913-2920. 2006. https://doi.org/10.1016/j.ces.2005.10.075

[16] Driss, Z., Bouzgarrou, G., Chtourou, W., Kchaou, H., Abid, M. S. "Computational studies of the pitched blade turbines design effect on the stirred tank flow characteristics." European Journal of Mechanics - B/ Fluids. 29(3), pp. 236-245. 2010.

https://doi.org/10.1016/j.euromechflu.2010.01.006

[17] Devi, T. T., Kumar, B. "Large-eddy simulation of turbulent flow in stirred tank with a curved blade impeller." Journal of Engineering Thermophysics. 24(2), pp. 152-168. 2015. https://doi.org/10.1134/S181023281502006X

[18] Youcefi, A. "Etude expérimentale de l'écoulement de fluide viscoélastique autour d'un agitateur bipale dans une cuve agitée", (Experimental study of viscoelastic fluid flow around two-blade impeller in a stirred vessel), $\mathrm{PhD}$ Thesis, Ecole Nationale Polytechnique (National Polytechnic Institute), Toulouse, 1993. (in French)

[19] Abid, M., Xuereb, C.; Bertrand, J. "Modeling of the 3D hydrodynamics of 2-blades impellers in stirred tanks filled with a highly viscous fluid." The Canadian Journal of Chemical Engineering. 72(2), pp. 184-193. 1994. https://doi.org/10.1002/cjce.5450720202

[20] Bouzit, M., Benali, L., Hachemi, M., Bouzit, F. "CFD Simulations of the 3D Velocity Profile of Paddle Agitator and Two-blade Impeller in Stirred Vessel with a Highly Viscous Newtonian Fluid." Journal of Applied Sciences. 6(13), pp. 2733-2740. 2006. https://doi.org/10.3923/jas.2006.2733.2740

[21] Ameur, H., Bouzit, M. "Power consumption for stirring shear thinning fluids by two-blade impeller." Energy. 50, pp. 326-332. 2013. https://doi.org/10.1016/j.energy.2012.11.016

[22] Youcefi, S., Youcefi, A. "Power consumption and mixing time in rheologically complex fluids by a two-bladed impeller." Journal of Mechanical Science and Technology. 29(2), pp. 543-548. 2015. https://doi.org/10.1007/s12206-015-0114-1

[23] Liu, B., Zheng, Y., Huang, B., Qian, L., Jin, Z. "The influence of feeding location on the micro mixing performance of novel large-double-blade impeller." Journal of the Taiwan Institute of Chemical Engineers. 52, pp. $65-71.2015$. https://doi.org/10.1016/j.jtice.2015.02.012

[24] Abbott, M. S. R., Perez, G. V., Harvey, A. P., Theodorou, M. K. "Reduced power consumption compared to a traditional stirred tank reactor (STR) for enzymatic saccharification of alpha-cellulose using oscillatory baffled reactor (OBR) technology." Chemical Engineering
Research and Design. 92(10), pp. 1969-1975. 2014.

https://doi.org/10.1016/j.cherd.2014.01.020

[25] Kato, Y., Yasui, N., Furukawa, H., Nagumo, R. "Effect of Liquid Height on Power Consumption of Two-Blade Wide Paddle Impeller." Kagaku Kogaku Ronbunshu. 42(6), pp. 187-191. 2016.

https://doi.org/10.1252/kakoronbunshu.42.187

[26] Haitsuka, M., Kamei, N., Kato, Y., Kamiya, M., Furukawa, H., Nagumo, R. "Power Consumption and Mass Transfer of High Viscosity Liquid in Gas-Liquid Mixing Vessel with Large Paddle Impeller." Kagaku Kogaku Ronbunshu. 42(5), pp. 174-178. 2016.

https://doi.org/10.1252/kakoronbunshu.42.174

[27] Tanabe, H., Misumi, R., Kaminoyama, M., Nishi, K. "Investigation of Torque and Horizontal Load on a Paddle Impeller in Eccentric Mixing." Journal of Chemical Engineering of Japan. 51(3), pp. 197-202. 2018. https://doi.org/10.1252/jcej.17we016

[28] Nishi, K., Bando, Y., Misumi, R., Kaminoyama, M. "Starting Torque of Vertical Paddle Impellers." Journal of Chemical Engineering of Japan. 50(9), pp. 677-683. 2017. https://doi.org/10.1252/jcej.16we353

[29] Furukawa, H., Kato, Y., Kato, T., Tada, Y. "Power Correlations and Mixing Patterns of Several Large Paddle Impellers with Dished Bottoms." Journal of Chemical Engineering of Japan. 46(4), pp. 255-261. 2013. https://doi.org/10.1252/jcej.12we228

[30] Ameur, H. "Mixing of a Viscoplastic Fluid in Cylindrical Vessels Equipped with Paddle Impellers." ChemistrySelect. 2(35), pp. 11492-11496. 2017. https://doi.org/10.1002/slct.201702459

[31] Ameur, H. "Mixing of complex fluids with flat and pitched bladed impellers: Effect of blade attack angle and shear-thinning behavior." Food and Bioproducts Processing. 99, pp. 71-77. 2016.

https://doi.org/10.1016/j.fbp.2016.04.004

[32] Alfaro-Ayala, J. A., Ayala-Ramírez, V., Gallegos-Muñoz, A., UribeRamírez, A. R. "Optimal location of axial impellers in a stirred tank applying evolutionary programing and CFD." Chemical Engineering Research and Design. 100, pp. 203-211. 2015.

https://doi.org/10.1016/j.cherd.2015.05.036

[33] Ameur, H. "Effect of some parameters on the performance of anchor impellers for stirring shear-thinning fluids in a cylindrical vessel." Journal of Hydrodynamics, Ser. B. 28(4), pp. 669-675. 2016.

https://doi.org/10.1016/S1001-6058(16)60671-6

[34] Higbee, R. W., Giacomelli, J. J., Wyczalkowski, W. R. "Advanced impeller design: Anti-ragging impeller, ARI2." Chemical Engineering Research and Design. 91(11), pp. 2190-2197. 2013.

https://doi.org/10.1016/j.cherd.2013.04.020

[35] Aubin, J., Fletcher, D. F., Xuereb, C. "Modelling turbulent flow in stirred tanks with CFD: the influence of the modelling approach, turbulence model, and numerical scheme." Experimental Thermal and Fluid Science. 28(5), pp. 431-445. 2004.

https://doi.org/10.1016/j.expthermflusci.2003.04.001

[36] Buwa, V., Dewan, A., Nasser, A. F., Durst, F. "Fluid dynamics and mixing of single-phase flow in a stirred vessel with a grid disc impeller: Experimental and numerical investigations." Chemical Engineering Science. 61(9), pp. 2815-2822. 2006. https://doi.org/10.1016/j.ces.2005.10.066

[37] Letellier, B., Xuereb, C., Swaels, P., Hobbes, P., Bertrand, J. "Scale-up in laminar and transient regimes of a multi-stage stirrer, a CFD approach." Chemical Engineering Science. 57(21), pp. 4617-4632. 2002. https://doi.org/10.1016/S0009-2509(02)00371-8

[38] Pakzad, L., Ein-Mozaffari, F., Upreti, S. R., Lohi, A. "Characterisation of the mixing of non-Newtonian fluids with a scaba 6SRGT impeller through ERT and CFD." The Canadian Journal of Chemical Engineering. 91(1), pp. 90-100. 2013. https://doi.org/10.1002/cjce.21616 
[39] Sommerfeld, M., Decker, S. "State of the Art and Future Trends in CFD Simulation of Stirred Vessel Hydrodynamics." Chemical Engineering and Technology. 27(3), pp. 215-224. 2004.

https://doi.org/10.1002/ceat.200402007

[40] Kukuková, A., Moštěk, M., Jahoda, M., Machoň, V. "CFD Prediction of Flow and Homogenisation in a Stirred Vessel: Part I Vessel with One and Two Impellers." Chemical Engineering and Technology. 28(10), pp. 1125-1133. 2005.

https://doi.org/10.1002/ceat.200500094

[41] Ameur, H. "3D hydrodynamics involving multiple eccentric impellers in unbaffled cylindrical tank." Chinese Journal of Chemical Engineering. 24(5), pp. 572-580. 2016.

https://doi.org/10.1016/j.cjche.2015.12.010

[42] Ameur, H. "Effect of the shaft eccentricity and rotational direction on the mixing characteristics in cylindrical tank reactors." Chinese Journal of Chemical Engineering. 24(12), pp. 1647-1654. 2016.

https://doi.org/10.1016/j.cjche.2016.05.011 